\title{
Adenocarcinomas after Prophylactic Surgery for Familial Adenomatous Polyposis
}

\author{
Joan C. Smith ${ }^{1}$, Michael W. Schäffer ${ }^{1}$, Billy R. Ballard ${ }^{2}$, Duane T. Smoot ${ }^{3}$, Alan J. Herline ${ }^{4}$, \\ Samuel E. Adunyah ${ }^{1,5}$, Amosy E. M’Koma ${ }^{1,4,5 \#}$ \\ ${ }^{1}$ Laboratory of Inflammatory Bowel Disease Research, Division of Biomedical Sciences, Department of Biochemistry and Cancer \\ Biology, Meharry Medical College School of Medicine, Nashville, Tennessee; ${ }^{2}$ Department of Pathology, Meharry Medical School \\ of Medicine, Nashville, Tennessee; ${ }^{3}$ Department of Internal Medicine, Meharry Medical College School of Medicine, Nashville, \\ Tennessee; ${ }^{4}$ Department of General Surgery, Vanderbilt University School of Medicine, Nashville, Tennessee; ${ }^{5}$ Vanderbilt-Ingram \\ Cancer Center, Vanderbilt University School of Medicine, Nashville, Tennessee. \\ Email: *amkoma@mmc.edu
}

Received September $29^{\text {th }}$, 2012; revised October 31 $1^{\text {st }}$, 2012; accepted November $7^{\text {th }}, 2012$

\begin{abstract}
The incidence of familial adenomatous polyposis (FAP) is one in 7000 to 12,000 live births. Virtually, all surgically untreated patients with FAP inevitably develop colorectal-cancer in their lifetime because they carry the adenomatous polyposis coli gene. Thus prophylactic proctocolectomy is indicated. Surgical treatment of FAP is still controversial. There are however, four surgical options: ileorectal anastomosis, restorative proctocolectomy with ileal pouch-anal anastomosis, proctocolectomy with ileostomy, and proctocolectomy with continent-ileostomy. Conventional proctocolectomy options largely lie between colectomy with ileorectal anastomosis or ileal pouch-anal anastomosis. Detractors of ileal pouch-anal anastomosis prefer ileorectal anastomosis because of better functional results and quality of life. The functional outcome of total colectomy with ileorectal anastomosis is undoubtedly far superior to that of the ileoanal pouch; however, the risk for rectal cancer is increased by 30\%. Even after mucosectomy, inadvertent small mucosal residual islands remain. These residual islands carry the potential for the development of subsequent malignancy. We reviewed the literature (1975-2012) on the incidence, nature, and possible etiology of subsequent ileal-pouch and anal transit zone adenocarcinoma after prophylactic surgery procedure for FAP. To date there are 24 studies reporting 92 pouch-related cancers; 15 case reports, 4 prospective and 5 retrospective studies. Twenty three of 92 cancers (25\%) developed in the pouch mucosa and 69 (75\%) in anal transit zone (ATZ). Current recommendation for pouch surveillance and treatment are presented. Data suggest lifetime surveillance of these patients.
\end{abstract}

Keywords: Familial Adenomatous Polyposis; Restorative Proctocolectomy; Ileal Pouch-Anal Anastomosis; Ileorectal Anastomosis; Adenocarcinomas

\section{Introduction}

Colorectal cancer remains a major problem in the treatment of patients with Familial adenomatous polyposis (FAP). Nearly one-fourth of these patients have colorectal cancer at initial operation, and one-fourth of patients will develop rectal cancer during surveillance follow-up. Many people with colorectal cancer experience no symptoms in the early stages of the disease. When symptoms appear, they will likely vary, depending on the cancer's size and location in the large intestine. Clinical manifestation of CRC may include: a change in bowel habits,

*All the authors substantially not only contributed to conception and design but also participated in the acquisition of data, analysis and interpretation of data and drafting the manuscript. The authors declare no competing financial interests.

${ }^{*}$ Corresponding author. including diarrhea or constipation or a change in the consistency of stool, rectal bleeding or blood in the stool, persistent abdominal discomfort, such as cramps, gas or pain, a feeling that the bowel doesn't empty completely, weakness or fatigue and unexplained weight loss.

FAP is an inherited autosomal dominant disease caused by mutations in the adenomatous polyposis coli (APC) gene located on chromosome 5q 21 - q 22 [1-4]. The incidence of FAP is one in 7000 to 12,000 live births $[5,6]$. If FAP patients are not surgically treated virtually all will develop adenocarcinoma in their lifetime [7-10]. The disease is characterized by hundreds of colorectal adenomas leading to a $100 \%$ lifetime transformation of colorectal cancer (CRC) if the colon is not removed [5, 11]. CRC has been incriminated as the main cause of death in FAP patients [12-14]. A prophylactic colec- 
tomy/total proctocolectomy (TPC) is therefore advocated for such patients to prevent CRC [15]. However, all somatic cells carry the APC gene, while FAP patient cells have a germline mutated $A P C$ gene. Thus even the ileal mucosa has the potential for malignant transformation [16]. Four surgical options are available for patients with FAP: $[17,19,20]$ colectomy with ileorectal anastomosis (IRA), restorative proctocolectomy (RPC) with ileal pouch-anal anastomosis (IPAA), proctocolectomy with ileostomy, and proctocolectomy with continent ileostomy (Kock). Surgical treatment via TPC with mucosectomy to the dentate line is observed to reduce the incidence of cancer in the anal transit zone (ATZ) [21-23] and a restorative IPAA preserves trans-anal defecation, but inadvertent small mucosal residual islands may remain $[4,24]$. Hence a subsequent development of malignnancy may be inevitable [4]. RPC is an alternative procedure to IRA $[5,26]$. The power of disease itself is the factor which determines the type of operation. While total colectomy with IRA provides superior functional results because it leaves the rectum intact, patients remain at a higher probability, compared to IPAA, of developing rectal cancer [2,27]. After IRA, 30\% of FAP patients develop rectal cancer before the age of 60 years with an average mortality of about $25 \%$ [28]. This development relates to the time before the surgical interventions of the 1980s, when surgical options were much more limited. This review includes reports of carcinomas appearing not only in the residual rectal mucosa or anastomosis after IRA $(10 \%-31 \%)$ but also in the ileal pouch body mucosa after Kock or IPAA ( $8 \%-62 \%)$ [29-38].

\section{Surgery}

The aim of surgical treatment of FAP is to intervene in the polyp-cancer sequence by removing the polyps before the transformation to malignancy occurs $[21,39,40]$. To date, there are no standardized guidelines as to when TPC or IRA or IPAA should be offered to patients, and there is no consensus about which surgical procedure is the better first-line treatment $[18,41]$. The difficulty of course is that the power of disease itself is the factor which determines the type of operation. Thus in a polyposis population correctly selected for RPC the alternative is TPC, since in both cases at the point of decision colectomy with IRA is no longer a surgical option. However, there are factors to be considered in the surgical decision process. The advantages and disadvantages, indications, contraindications, and timing for surgery are depicted in Table 1.

\section{Colectomy with Ileorectal Anastomosis}

An IRA can be defined as removal of the entire colon, leaving $15 \mathrm{~cm}$ of rectum for optimal bowel function $[4,42,43]$. Triaging the fate of the rectum according to the number, size, and histology of rectal polyps is effective in minimizing the need for future proctectomy. If there are fewer than 20 adenomas, none larger than $1 \mathrm{~cm}$ and none dysplastic, the rectum may be retained [42]. The IRA preserves excellent bowel function, is simple, and can be done with major benefits to the lifestyle of patients [43].

\section{Restorative Proctocolectomy with Ileal-Pouch Anal Ansatomosis}

RPC with IPAA requires removal of the entire colon and rectum down to the pelvic floor achieving significant prevention of both colon and rectal cancer but needs construction of an ileal pouch. An anastomosis between an ileal pouch and the upper anus is performed. There are three options that affect the conduct of the operation: the type of pouch, the type of anastomosis, and construction of a diverting loop ileostomy.

\section{Type of Pouch}

There are different pouch conformations (J-, S-, W-, and $\mathrm{H}$-shaped) [17]. The most common and easiest pouch to make is the J-shaped pouch [44]. Limbs are 15 to $20 \mathrm{~cm}$ long but the main factor determining length is the position of the apex of the superior mesenteric artery [17].

\section{Type of Anastomosis}

The simpler type of anastomosis is a double-stapled end of pouch to anus anastomosis [45]. The rectum is stapled distally at the level of the pelvic floor, a purse string suture is inserted into the open end of the pouch and used to tie in the anvil of the stapler, and the anastomosis is completed by transanal insertion of the stapler cartridge; uniting the cartridge with the anvil and firing the stapler. Residual anal transition zone is often less than $1.0 \mathrm{~cm}$, as the stapler removes 0.5 to $1.0 \mathrm{~cm}$. Alternatively, the ATZ is mucosectomized and the pouch pulled into the anus and anastomosed by hand transanally to the dentate line. The stripping and hand-sewn anastomosis takes longer and in some studies is associated with more complications and poorer function than the stapled anastomosis [46], but its putative advantage is removal of all anal transitional and rectal epithelium with more complete prevention of anal transitional neoplasia [18].

\section{Diversion of Loop Ileostomy}

Patients with FAP are at low risk for an anastomotic leak or fistula because they are generally healthy, are not taking immunosuppressive medications, and have normal bowel except for the adenomas. Although an ileostomy 
Table 1. Indications, contraindications, advantages and disadvantages summarized of surgical options for patients with FAP.

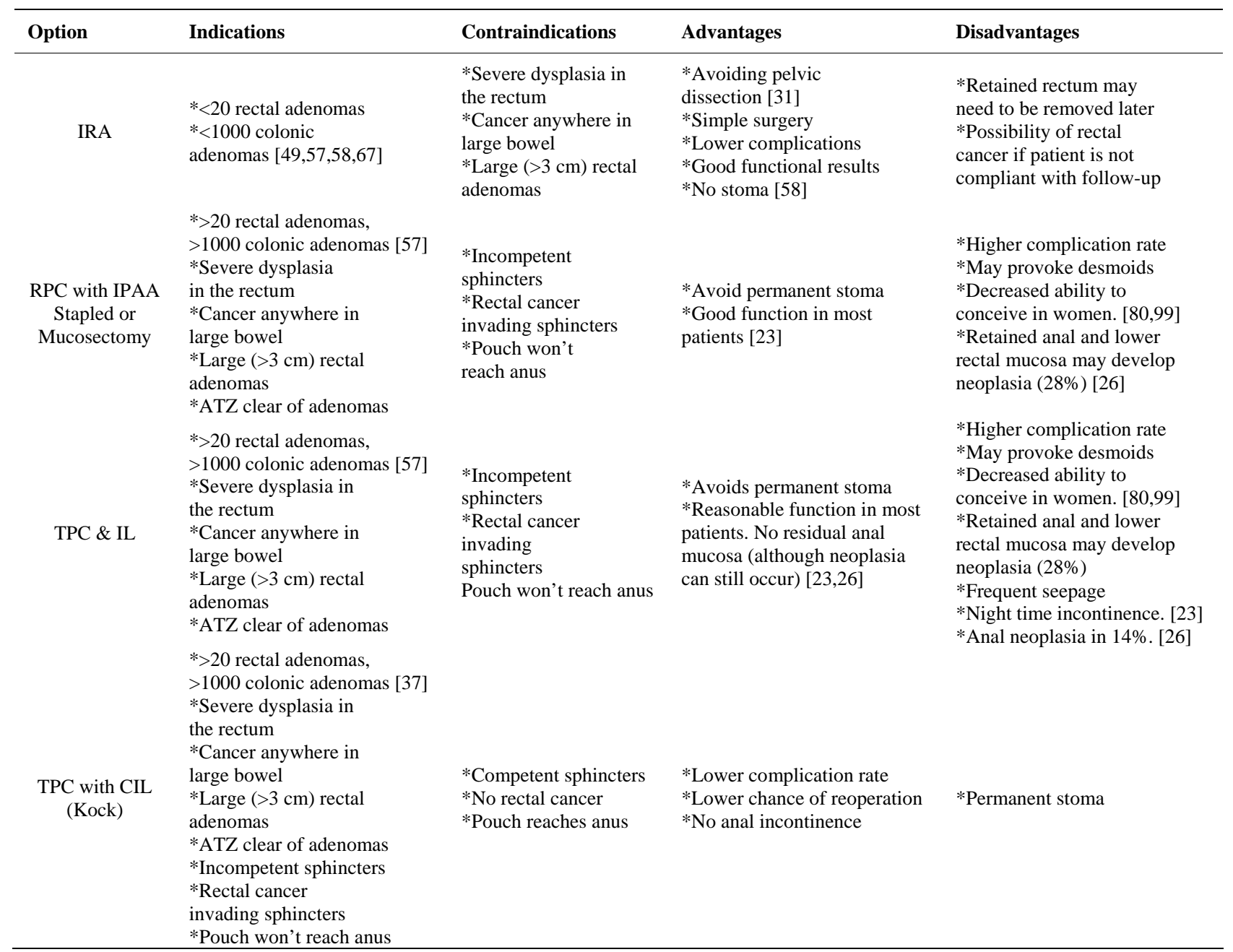

Abbreviation: IRA = Ileorectal anastomosis, RPC = Restorative proctocolectomy, IPAA = Ileal pouch-anal anastomosis, TPC \& IL = Proctocolectomy and Ileostomy, TPC with CIL = Proctocolectomy with continent ileostomy (Kock), ATZ = Anal transit zone.

creates the need for another surgery for closure and has its own risks of postoperative complications, an undiverted pouch is at a higher risk of anastomotic leak [47]. Therefore, in most patients a "safety first" approach is better and the postoperative course is smoother. To our knowledge, to date, there are no published data available on the relationship between establishments or not of a diverting loop ileostomy and the incidence of cancer development of the pouch or ATZ.

\section{Diagnosis}

Pouch cancer is typically diagnosed on surveillance pouchoscopy and/or incidentally detected on diagnostic pouchoscopy. Metastasis to lymph nodes or distant organs at the time of cancer diagnosis is not uncommon. Pouch mucosa should be deemed as having malignant potential once polyps 1 - $3 \mathrm{~mm}$ in size with high-grade dysplasia in one of them is detected and practicing physicians should remain vigilant. Because most pouch-related adenocarcinoma is located at the ATZ, digital examination of the area may suggest areas harboring cancer and a full examination under anesthesia in the operating room is warranted.

\section{Treatment}

When rectal or pouch cancer is diagnosed the role of IPAA is uncertain because of concerns that may compromise oncologic therapy and oncologic therapy may compromise IPAA function. Most patients in this review had their pouch removed (pouchectomized) with permanent re-stoma. Adjuvant chemotherapy or radiotherapy or both was not commonly practiced and when it was prescribed complications such as enteritis and or pouch failure requiring dose reduction or interruption was commonly observed.

Patients with IRA need proctoscopy in 6 months to a 
year to monitor the rectum [48]. When polyps start to grow, small $(<5 \mathrm{~mm})$ lesions can be ignored whereas large $(>5 \mathrm{~mm})$ are snared [48]. Chemoprophylaxis with Sulindac or Celebrex may minimize adenoma growth but will not necessarily prevent cancer [49]. They can be used for patients with significant polyp burden but who are not ready or suitable for proctectomy. Further, patients who have had IPAA need close lifelong endoscopic surveillance as well $[13,50]$. The incidence is time-dependent from surgery [29]. Mucosectomy does not guarantee complete excision of rectal epithelium and cancer still occurs in these patients [2,5,51]. This is not surprising, considering the additional combination of fecal stasis [52], a germline $A P C$ mutation, and rapid epithelial turnover [53-56].

Some patients (IPAA and IRA) are treated endoscopically within the ileal mucosa using argon plasma coagulation $[57,58]$. There is evidence that indicators for proctectomy after IRA include an increasing instability of the rectal mucosa as evidenced by increasing polyp size or number [6]. Severe dysplasia is also an indication, as is cancer. In most cases, proctectomy and IPAA can be done although occasionally an IPAA is not possible because of inadequate bowel length or mesenteric desmoids tumors.

\section{Natural History of Adenocarcinoma after Surgery for Fap}

When fecal stasis occurs such as in the pouch, the incidence of neoplasia in ileal pouch mucosa may increase $[2,59]$. It appears that the causative sequence starts with a chronic inflammatory process leading to a colonic-type epithelial metaplasia [30,60,61]. It is thought that cytological atypia and architectural abnormalities may ensue in a process of dysplasia that eventually may lead to carcinoma.

Until the age of 50 years, the cumulative risk of rectal carcinoma after FAP-IRA has been shown to be $10 \%$, increasing sharply to $30 \%$ by the age of 60 years $[19,28]$. This indicates that surveillance of the retained rectum in older patients must either be improved or they should undergo a complete proctectomy (with or without ileoanal pouch) in early middle age. The five year survival rate of patients with FAP developing rectal cancer after RPC is reported to be $71 \%$ [62]. Penna et al. reported seven cases of rectal carcinoma in a series of 29 cases (24\%) with IRA for FAP [63]. Three carcinomas were diagnosed prior to surgery, but four at the time of surgery [63]. Moreover; Heiskanen and Jarvinen observed nine cases of rectal carcinoma (9\%) that developed among 100 patients with FAP treated with IRA, although surveillance was performed [64]. This means that even close surveillance, though highly recommended, cannot guar- antee the prevention of rectal carcinoma. It is also not clearly known whether there is a metaplasia-dysplasiacarcinoma sequence following pouch surgery, or if there is simply increased risk of sporadic cancer in the ileal pouch of certain susceptible individuals. Further studies are needed for clarity.

Controversies exist about the danger of developing carcinoma in the remaining rectum after colectomy and IRA. The degree of probability varies from series to series, from $0 \%$ at the Cleveland Clinic [2] to 32\% at Mayo Clinic [25]. The discrepancies are not clear, but it appears that the chance of developing carcinoma increases with time [9,65]. Although carcinoma is rare before the age of 20 in patients with FAP, a study from Mayo Clinic reported three cases, two of which were in the rectum and undetected preoperatively [15].

Although a number of groups have provided surveillance options for diagnosis and treatment of the ileal pouch cancer lesions, no standardized treatment guidelines have gained acceptance in general medical practice. Saurin et al. [66] illustrated the methods of surveillance and possible therapeutic indications in patients with FAP following colectomy [67,68]. Despite there being no validated data in the literature; on the basis of experience, follow-ups should happen six months and one to two years after surgery [66].

\section{Literature Review}

A systematic literature search using Medline, PubMed, and Google Scholar from 1975 through 2012 was systematically reviewed. Secondary and hand searches of reference lists, other studies cross-indexed by authors, reviews, commentaries, books and meeting abstracts were also performed. The search terms included: FAP, colectomy, total proctocolectomy, ileorectal anastomosis, Kock pouch, continent ileostomy, restorative proctocolectomy, ileal pouch-anal anastomosis and mucosectomy-consisting of case reports, prospective and retrospective studies reporting postoperative pouch related adenocarcinoma adverse events of patients' undergone prophylactic surgery for FAP. Studies were included only if the cancers were clearly within ileal pouch mucosa and/ or ATZ. The search excluded non-English language and non-human studies as well as five editorials.

\section{Postoperative Surveillance}

Patients were followed up for an average period of 5.8 (1.5 to 46.4) years. Fewer than $20 \%$ in China to $37.1 \%$ to $54.5 \%$ [9] in the UK of FAP patients have had a regular postoperative follow-up visits [69]. The failure of surveillance is seen differently based on geographical, economical and cultural stigma [9,69]. The mean duration of pouch endoscopic follow-up was $6.2 \pm 4.1$ years. Al- 
though, the median age and median follow-up duration of IRA patients (13.5 years) was longer than that of the IPAA patients (10.3 years), there was no statistically significant difference. Complication rates of IPAA and IRA were deemed to be indifferent [70,71]. The functional outcome of the IRA is observed superior to that of the IPAA; however the function of an IPAA after an IRA is similar to that of a de novo pouch [72-74].

\section{Adenocarcinoma of Ileal Pouch and Anal Transit Zone}

To date there are 24 articles reporting cancers in connection with pouch surgery for FAP; 15 case reports, 4 prospective and 5 retrospective studies, Table 2. Currently there are 92 FAP-pouch-related cancers reported, 23 of $92(25 \%)$ cases arising in the ileal pouch mucosa and 69 (75\%) developed in the ATZ [75,76]. Multivariate analysis of the risk of cancer formation in the anorectal segment was associated with stapled ileoanal anastomosis (IAA) and age at RPC older than 40 years and was independent predictors of cancer formation, Table 2 . There is a reported correlation between risk of cancer incidence and age at pouch surgery and the type of anastomosis (stapled vs. handsewn), $p<0.001$, Table 3.

The mean age of patients at FAP diagnosis was 30.6 years and the median age at the time of pouch surgery was 41 years. More cancers developed in those between 50 and 60 years of age. However, because of a few younger patients, the mean age of development of pouch anal cancer was 48.3 years.

Conventional TPC is indicated and the surgical options largely lie between IRA or RPC [17,77-85] for patients with FAP. RPC with IPAA offers the best available prophylaxis and is considered the criterion surgical procedure [77]. However, subsequent malignancies originating from residual mucosa may develop in the pouch and the IAA. Therefore, ileoanal pouch (IAP) mucosa and the anorectal mucosa below the IAA are potential areas for undergoing malignant transformation [81]. The cause of true pouch cancer seems to be different from the cancer arising from residual rectal or anal transitional epithelium, and the risks associated with these true pouches are controversial [16]. It has been suggested that TPC may not be a "cancer free" alternative to IRA [86]. Incidence of cancer in the ATZ in mucosectomized, handsewn IPAA, and stapled IPAA in patients with FAP have been reported in a study by von Roon et al. [9] they surveyed 140 patients out of 260 who were followed-up endoscopically for a median of 10.3 years after RPC. Fiftytwo patients (37\%) developed neoplastic transformation in the anorectal segment, with a cumulative risk at 10 years of $22.6 \%$ after mucosectomy with manual anastomosis and $51.1 \%$ after stapled IAA $(p<0.001)$.

\section{Causes of Death}

Although the effects of prophylactic colectomy on prognosis and survival are encouraging, the cancer problem is not finished even after curative surgery for FAP $[13,87]$. The attendance rate for surveillance colonoscopy is of utmost importance [72,88-90]. CRC is the main cause of death in this population, but it is progressively less common within families under surveillance, occurring almost exclusively in individuals exhibiting new mutations and with no family history of the syndrome [91,92]. In the Finnish polyposis Registry experience, rectal stump cancer was the second cause of death. In a group of 236 FAP, primary CRC occurred in $18.2 \%$ and rectal cancer after IRA was the cause in $4.6 \%$, comprising nearly one fifth of all FAP-related causes [87]. Arvantis et al. [91] had reported that cancer caused $8.3 \%$ of all deaths after prophylactic colectomy. Yan et al. [69] had similar observations mostly due to liver metastasis and advanced rectal cancer. This risk was addressed in long-term follow-up studies, suggesting that a more frequent indication of RPC instead of IRA may improve life expectancy by reducing rectal stump cancer rates [87,93]. Data from the St. Marks Hospital had previously shown a three-fold relative risk of death after IRA [94].

\section{Conclusion}

Surgical treatment of FAP is still controversial and the choice between IPAA and IRA procedures is still a matter of debate. IPAA remains the alternative to IRA for the prophylactic treatment of FAP. The incidence of cancers in the anal canal (10\% - 31\%) and ileal pouch (8\% - 62\%) is apparent. Where there are polyps encroaching on the pectinel line, a mucosectomy should be indicated, but it is also noteworthy that this does not necessarily eliminate evolution risks. Most importantly, regardless of the anastomotic technique used, careful regular endoscopic surveillance of all patients surgically treated for FAP and having retained functionally acceptable pouches is critical.

\section{Acknowledgements}

We acknowledge all scientists who made contributions to the areas of research reviewed but were not cited due to space constraints.

\section{Source of Support}

3U54CA09140809S1 (MMC-VICC cancer partnership); MeTRC grant \# 5U 54RR026140-03; Vanderbilt CTSA grant \# 1 UL1 RR024975/NCRR/NIH; Research Foundation, American Society of Colon and Rectal Surgeons (ASCRS)-LPG-086; Vanderbilt CTSA grant 1 ULI 
Table 2. Summary of published data of the incidence of adenocarcinomas after prophylactic surgery for FAP. This table underscores the fact that mucosectomy does not necessarily prevent the development of adenomas in the ATZ.

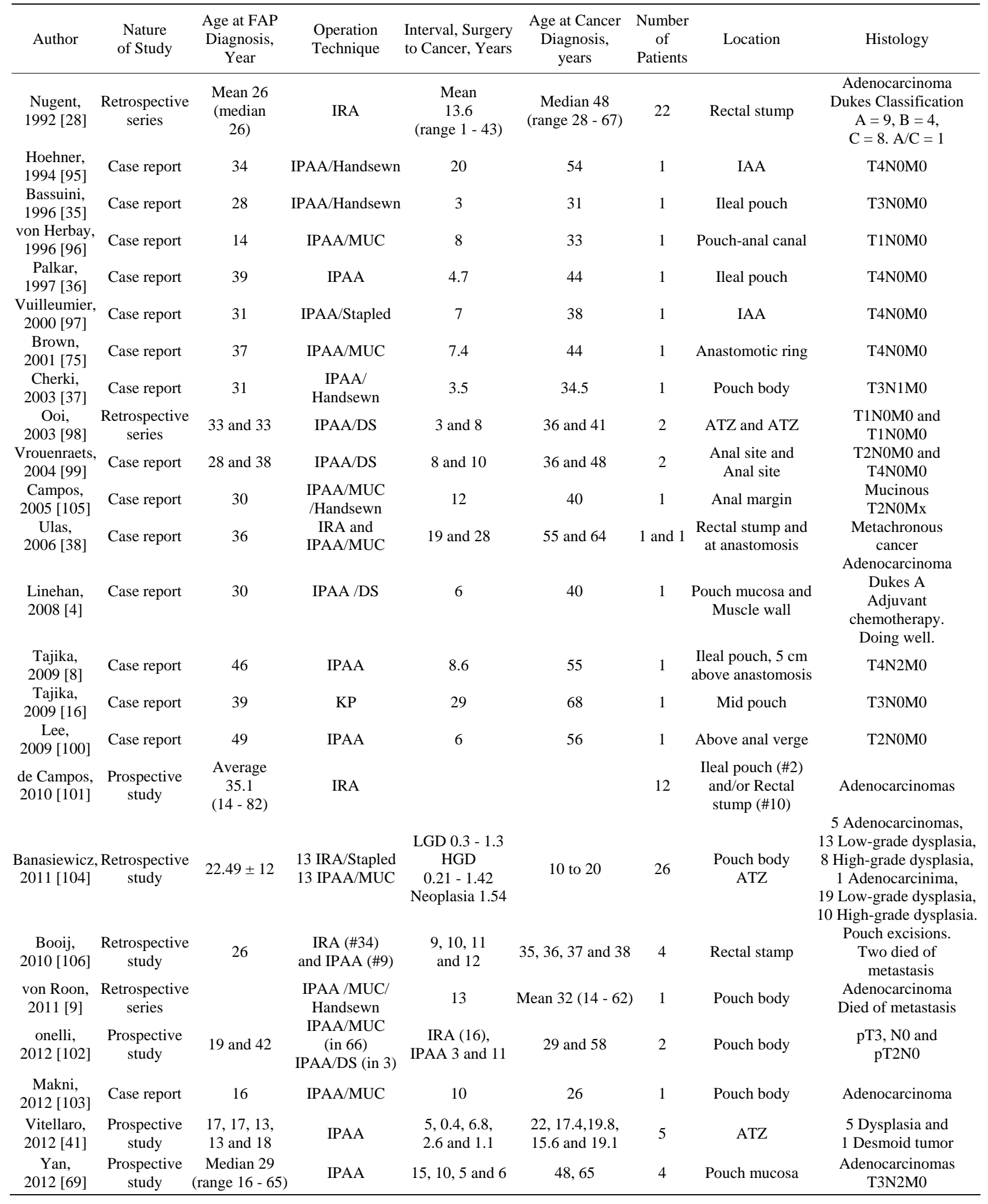

Abbreviations: IPAA = Ileo-pouch anal anasto-mosis; DS = Double stapled; LGD = Low-grade dysplasia; KP = Kock pouch; FAP = Familai adenomatous polyposis; HGD = High-grade dysplasia; PP = Pouch polyposis; ATZ = Anal transtional zone; VA = Villous adenoma; RPC = Restorative proctocolectomy; IRA = Ileal rectal anastomosis; MUC = Mucosectomy. 
Table 3. Incidence of (adenomas and) cancer in the ATZ in mucosectomized, handsewn IPAA and stapled IPAA in patients with FAP.

\begin{tabular}{|c|c|c|c|c|c|c|}
\hline Author & Follow-up-yrs & $\begin{array}{l}\text { Number of patients } \\
\text { followed-up } \\
\text { in the study }\end{array}$ & $\begin{array}{c}\text { Number of patients } \\
\text { developed neoplastic } \\
\text { transformation }\end{array}$ & $\begin{array}{l}\text { IPAA with mucosectomy } \\
\text { that developed } \\
\text { neoplastic transformation }\end{array}$ & $\begin{array}{l}\text { IRA Stapled that } \\
\text { developed neoplastic } \\
\text { transformation }\end{array}$ & $P$-value \\
\hline $\begin{array}{c}\text { von Roon } \\
\text { et al., } 2011 \text { [9] }\end{array}$ & 10.3 (median) & 140 & $52(37 \%)$ & $22.6 \% \%$ & $51.1 \%$ & 0.001 \\
\hline $\begin{array}{c}\text { Friedrech } \\
\text { et al., } 2008 \text { [107] }\end{array}$ & 6.8 (range 0.4 - 20.3) & 212 & $74(35 \%)$ & $29 \%$ & $64 \%$ & 0.0004 \\
\hline $\begin{array}{c}\text { von Roon } \\
\text { et al., } 2007 \text { [23] }\end{array}$ & 5 (range 0.1 - 24.75) & 91 & $24(26 \%)$ & $11(19 \%)$ & $13(38) \%$ & 0.047 \\
\hline $\begin{array}{c}\text { Remzi } \\
\text { et al., } 2001 \text { [21] }\end{array}$ & 5.8 vs. 3.6 & 119 & $44(58 \%)$ & $\begin{array}{l}9 \text { of } 42(21 \%) \text { in the } \\
\text { pouch and } 6 \text { of } 42 \text { had it } \\
\text { in mucosectomized ATZ }\end{array}$ & $\begin{array}{c}21 \text { of } 76(28 \%) \text { in ATZ and } \\
8(11 \%) \text { had adenomas } \\
\text { in the pouch body mucosa }\end{array}$ & \\
\hline $\begin{array}{l}\text { Van Duijvendijk } \\
\text { et al., } 1999 \text { [22] }\end{array}$ & $\begin{array}{c}\text { Median 5.5, } \\
\text { (range } 1 \text { - 1.7) }\end{array}$ & 97 & 48 & 13 & 35 & 0.01 \\
\hline
\end{tabular}

RR024975 (NCRR/NIH); and 5P 30 DK58404-08 Silvio O. Conte Digestive Diseases Research Core Centers.

\section{REFERENCES}

[1] K. W. Kinzler, M. C. Nilbert, L. K. Su, et al., "Identification of FAP Locus Genes from Chromosome 5q21," Science, Vol. 253, No. 5020, 1991, pp. 661-665. doi:10.1126/science.1651562

[2] J. Church, "Ileoanal Pouch Neoplasia in Familial Adenomatous Polyposis: An Underestimated Threat," Diseases of the Colon \& Rectum, Vol. 48, No. 9, 2005, pp. 1708-1713. doi:10.1007/s10350-005-0057-1

[3] J. Groden, A. Thliveris, W. Samowitz, et al., "Identification and Characterization of the Familial Adenomatous Polyposis Coli Gene,” Cell, Vol. 66, No. 3, 1991, pp. 589-600. doi:10.1016/0092-8674(81)90021-0

[4] G. Linehan, R. A. Cahill, S. N. Kalimuthu, F. O’Connell, H. P. Redmond and W. O. Kirwan, "Adenocarcinoma Arising in the Ileoanal Pouch after Restorative Proctocolectomy for Familial Adenomatous Polyposis,” International Journal of Colorectal Disease, Vol. 23, No. 3, 2008, pp. 329-330. doi:10.1007/s00384-007-0400-1

[5] H. J. Bussey, A. M. Veale and B. C. Morson, "Genetics of Gastrointestinal Polyposis,” Gastroenterology, Vol. 74, No. 6, 1978, pp. 1325-1330.

[6] J. Church, "Familial Adenomatous Polyposis," Surgical Oncology Clinics of North America, Vol. 18, No. 4, 2009, pp. 585-598. doi:10.1016/j.soc.2009.07.002

[7] H. Bussey, "Familial Polyposis Coli: Family Studies, Histopathology, Differentially Diagnosis and Results of Treatment," The John Hopkins University Press, Baltimore, 1975.

[8] M. Tajika, T. Nakamura, O. Nakahara, et al., "Prevalence of Adenomas and Carcinomas in the Ileal Pouch after Proctocolectomy in Patients with Familial Adenomatous Polyposis,” Journal of Gastrointestinal Surgery, Vol. 13, No. 7, 2009, pp. 1266-1273. doi:10.1007/s11605-009-0871-1

[9] A. C. von Roon, O. C. Will, R. F. Man, et al., "Mucosectomy with Handsewn Anastomosis Reduces the Risk of Adenoma Formation in the Anorectal Segment after Restorative Proctocolectomy for Familial Adenomatous
Polyposis,” Annals of Surgery, Vol. 253, No. 2, 2011, pp. 314-317. doi:10.1097/SLA.0b013e318f3f498

[10] S. Bulow, "Mucosectomy and Stapled Pouch-Anal Anastomosis in Familial Adenomatous Polyposis," Colorectal Disease, Vol. 14, No. 1, 2012, pp. 68-70. doi:10.1111/j.1463-1318.2010.02509.x

[11] S. Baglioni and M. Genuardi, "Simple and Complex Genetics of Colorectal Cancer Susceptibility," American Journal of Medical Genetics Part C: Seminars in Medical Genetics, Vol. 129C, No. 1, 2004, pp. 35-43. doi:10.1002/ajmg.c.30023

[12] F. G. de Campos, R. O. Perez, A. R. Imperiale, V. E. Seid, S. C. Nahas and I. Cecconello, "Evaluating Causes of Death in Familial Adenomatous Polyposis," Journal of Gastrointestinal Surgery, Vol. 14, No. 12, 2010, pp. 1943-1949. doi:10.1007/s11605-010-1288-6

[13] F. G. Campos, A. Habr-Gama, D. R. Kiss, et al., “Adenocarcinoma after Ileoanal Anastomosis for Familial Adenomatous Polyposis: Review of Risk Factors and Current Surveillance Apropos of a Case,” Journal of Gastrointestinal Surgery, Vol. 9, No. 5, 2005, pp. 695-702.

[14] L. Bertario, S. Presciuttini, P. Sala, C. Rossetti and M. Pietroiusti, "Causes of Death and Postsurgical Survival in Familial Adenomatous Polyposis: Results from the Italian Registry. Italian Registry of Familial Polyposis Writing Committee,” Seminars in Surgical Oncology, Vol. 10, No. 3, 1994, pp. 225-234. doi:10.1002/ssu.2980100311

[15] Y. R. Parc, G. Moslein, R. R. Dozois, J. H. Pemberton, B. G. Wolff and J. E. King, "Familial Adenomatous Polyposis: Results after Ileal Pouch-Anal Anastomosis in Teenagers," Diseases of the Colon \& Rectum, Vol. 43, No. 7, 2000, pp. 893-898. doi:10.1007/BF02237346

[16] M. Tajika, T. Nakamura, V. Bhatia, K. Komori, T. Kato and K. Yamao, "Ileal Pouch Adenocarcinoma after Proctocolectomy for Familial Adenomatous Polyposis,” International Journal of Colorectal Disease, Vol. 24, No. 12, 2009, pp. 1487-1489. doi:10.1007/s00384-009-0776-1

[17] A. E. M'Koma, P. E. Wise, R. L. Muldoon, D. A. Schwartz, M. K. Washington and A. J. Herline, "Evolution of the Restorative Proctocolectomy and Its Effects on Gastrointestinal Hormones," International Journal of Colorectal Disease, Vol. 22, No. 10, 2007, pp. 1143-1163. doi:10.1007/s00384-007-0331-x

[18] O. Aziz, T. Athanasiou, V. W. Fazio, et al., "Meta-Ana- 
lysis of Observational Studies of Ileorectal versus Ileal Pouch-Anal Anastomosis for Familial Adenomatous Polyposis,” The British Journal of Surgery, Vol. 93, No. 4, 2006, pp. 407-417. doi:10.1002/bjs.5276

[19] C. Bulow, H. Vasen, H. Jarvinen, J. Bjork, M. L. Bisgaard and S. Bulow, "Ileorectal Anastomosis Is Appropriate for a Subset of Patients with Familial Adenomatous Polyposis," Gastroenterology, Vol. 119, No. 6, 2000, pp. 1454-1460. doi:10.1053/gast.2000.20180

[20] Y. Ziv, J. M. Church, J. R. Oakley, E. McGannon, T. K. Schroeder and V. F. Fazio, "Results after Restorative Proctocolectomy and Ileal Pouch-Anal Anastomosis in Patients with Familial Adenomatous Polyposis and Coexisting Colorectal Cancer," The British Journal of Surgery, Vol. 83, No. 11, 1996, pp. 1578-1580. doi:10.1002/bjs. 1800831128

[21] F. H. Remzi, J. M. Church, J. Bast, et al., "Mucosectomy vs. Stapled Ileal Pouch-Anal Anastomosis in Patients with Familial Adenomatous Polyposis: Functional Outcome and Neoplasia Control," Diseases of the Colon \& Rectum, Vol. 44, No. 11, 2001, pp. 1590-1596. doi:10.1007/BF02234377

[22] P. van Duijvendijk, H. F. Vasen, L. Bertario, et al., " $\mathrm{Cu}-$ mulative Risk of Developing Polyps or Malignancy at the Ileal Pouch-Anal Anastomosis in Patients with Familial Adenomatous Polyposis: Official Journal of the Society for Surgery of the Alimentary Tract," Journal of Gastrointestinal Surgery, Vol. 3, No. 3, 1999, pp. 325-330. doi:10.1016/S1091-255X(99)80075-4

[23] A. C. von Roon, P. P. Tekkis, S. K. Clark, et al., "The Impact of Technical Factors on Outcome of Restorative Proctocolectomy for Familial Adenomatous Polyposis,” Diseases of the Colon \& Rectum, Vol. 50, No. 7, 2007, pp. 952-961. doi:10.1007/s10350-006-0872-z

[24] P. R. O’Connell, J. H. Pemberton, L. H. Weiland, et al., "Does Rectal Mucosa Regenerate after Ileoanal Anastomosis?” Diseases of the Colon \& Rectum, Vol. 30, No. 1, 1987, pp. 1-5. doi:10.1007/BF02556908

[25] W. L. Ambroze Jr., R. R. Dozois, J. H. Pemberton, R. W. Beart Jr. and D. M. Ilstrup, "Familial Adenomatous Polyposis: Results Following Ileal Pouch-Anal Anastomosis and Ileorectostomy," Diseases of the Colon \& Rectum, Vol. 35, No. 1, 1992, pp. 12-15. doi:10.1007/BF02053332

[26] A. H. Kartheuser, R. Parc, C. P. Penna, et al., "Ileal Pouch-Anal Anastomosis as the First Choice Operation in Patients with Familial Adenomatous Polyposis: A TenYear Experience,” Surgery, Vol. 119, No. 6, 1996, pp. 615-623. doi:10.1016/S0039-6060(96)80185-1

[27] C. R. Newton and W. N. Baker, "Comparison of Bowel Function after Ileorectal Anastomosis for Ulcerative Colitis and Colonic Polyposis,” Gut, Vol. 16, No. 10, 1975, pp. 785-791. doi:10.1136/gut.16.10.785

[28] K. P. Nugent and R. K. Phillips, "Rectal Cancer Risk in Older Patients with Familial Adenomatous Polyposis and an Ileorectal Anastomosis: A Cause for Concern," The British Journal of Surgery, Vol. 79, No. 11, 1992, pp. 1204-1206. doi:10.1002/bjs.1800791136

[29] J. S. Wu, E. A. McGannon and J. M. Church, "Incidence of Neoplastic Polyps in the Ileal Pouch of Patients with Familial Adenomatous Polyposis after Restorative Proctocolectomy," Diseases of the Colon \& Rectum, Vol. 41, No. 5, 1998, pp. 552-556. doi:10.1007/BF02235258

[30] N. A. Shepherd, J. R. Jass, I. Duval, R. L. Moskowitz, R. J. Nicholls and B. C. Morson, "Restorative Proctocolectomy with Ileal Reservoir: Pathological and Histochemical Study of Mucosal Biopsy Specimens," Journal of Clinical Pathology, Vol. 40, No. 6, 1987, pp. 601-607. doi:10.1136/jcp.40.6.601

[31] M. W. Thompson-Fawcett, V. A. Marcus, M. Redston, Z. Cohen and R. S. McLeod, “Adenomatous Polyps Develop Commonly in the Ileal Pouch of Patients with Familial Adenomatous Polyposis," Diseases of the Colon \& Rectum, Vol. 44, No. 3, 2001, pp. 347-353. doi:10.1007/BF02234731

[32] Y. R. Parc, S. Olschwang, B. Desaint, G. Schmitt, R. G. Parc and E. Tiret, "Familial Adenomatous Polyposis: Prevalence of Adenomas in the Ileal Pouch after Restorative Proctocolectomy," Annals of Surgery, Vol. 233, No. 3, 2001, pp. 360-364. doi:10.1097/00000658-200103000-00009

[33] C. J. Groves, G. Beveridge, D. J. Swain, et al., "Prevalence and Morphology of Pouch and Ileal Adenomas in Familial Adenomatous Polyposis," Diseases of the Colon \& Rectum, Vol. 48, No. 4, 2005, pp. 816-823. doi:10.1007/s10350-004-0835-1

[34] T. Myrhoj, S. Bulow and A. M. Mogensen, "Multiple Adenomas in Terminal Ileum 25 Years after Restorative Proctocolectomy for Familial Adenomatous Polyposis. Report of a Case,” Diseases of the Colon \& Rectum, Vol. 32, No. 7, 1989, pp. 618-620. doi:10.1007/BF02554184

[35] M. M. Bassuini and P. J. Billings, "Carcinoma in an Ileoanal Pouch after Restorative Proctocolectomy for Familial Adenomatous Polyposis," The British Journal of Surgery, Vol. 83, No. 4, 1996, p. 506. doi:10.1002/bjs.1800830422

[36] V. M. Palkar, L. J. deSouza, P. Jagannath and K. N. Naresh, “Adenocarcinoma Arising in 'J' Pouch after Total Proctocolectomy for Familial Polyposis Coli,” Indian Journal of Cancer, Vol. 34, No. 1, 1997, pp. 16-19.

[37] S. Cherki, O. Glehen, V. Moutardier, Y. Francois, F. N. Gilly and J. Vignal, "Pouch Adenocarcinoma after Restorative Proctocolectomy for Familial Adenomatous Polyposis," Colorectal Disease, Vol. 5, No. 6, 2003, pp. 592-594. doi:10.1046/j.1463-1318.2003.00486.x

[38] M. Ulas, G. Nessar, A. Bostanoglu, et al., "Development of Two Cancers in the Same Patient after Ileorectal and Ileal Pouch Anal Anastomosis for Familial Adenomatous Polyposis,” Medical Principles and Practice, Vol. 15, No. 1, 2006, pp. 83-86. doi:10.1159/000089393

[39] K. D. Smith and M. A. Rodriguez-Bigas, "Role of Surgery in Familial Adenomatous Polyposis and Hereditary Nonpolyposis Colorectal Cancer (Lynch Syndrome)," Surgical Oncology Clinics of North America, Vol. 18, No. 4, 2009, pp. 705-715. doi:10.1016/j.soc.2009.07.006

[40] J. P. Lockhart-Mummery, "The Causes and Treatment of Pruritus Ani,” Postgraduate Medical Journal, Vol. 10, 1934, pp. 429-434. doi:10.1136/pgmj.10.110.429 
[41] M. Vitellaro, A. Ferrari, K. Trencheva, et al., "Is Laparoscopic Surgery an Option to Support Prophylactic Colectomy in Adolescent Patients with Familial Adenomatous Polyposis (FAP)?” Pediatric Blood Cancer, Vol. 59, No. 7, 2012, pp. 1223-1228. doi:10.1002/pbc.24113

[42] J. Church, C. Burke, E. McGannon, O. Pastean and B. Clark, "Predicting Polyposis Severity by Proctoscopy: How Reliable Is It?” Diseases of the Colon \& Rectum, Vol. 44, No. 9, 2001, pp. 1249-1254. doi:10.1007/BF02234779

[43] J. M. Church, V. W. Fazio, I. C. Lavery, J. R. Oakley, J. Milsom and E. McGannon, "Quality of Life after Prophylactic Colectomy and Ileorectal Anastomosis in Patients with Familial Adenomatous Polyposis," Diseases of the Colon \& Rectum, Vol. 39, No. 12, 1996, pp. 14041408. doi:10.1007/BF02054529

[44] J. Utsunomiya, T. Iwama, M. Imajo, et al., "Total Colectomy, Mucosal Proctectomy, and Ileoanal Anastomosis,” Diseases of the Colon \& Rectum, Vol. 23, No. 7, 1980, pp. 459-466. doi:10.1007/BF02987076

[45] J. Utsunomiya, M. Oota and T. Iwama, "Recent Trends in Ileoanal Anastomosis,” Annales Chirurgiae et Gynaecologiae, Vol. 75, No. 2, 1986, pp. 56-62.

[46] Y. Ziv, V. W. Fazio, J. M. Church, I. C. Lavery, T. M. King and P. Ambrosetti, "Stapled Ileal Pouch Anal Anastomoses Are Safer than Handsewn Anastomoses in Patients with Ulcerative Colitis," The American Journal of Surgery, Vol. 171, No. 3, 1996, pp. 320-323. doi:10.1016/S0002-9610(97)89634-1

[47] G. K. Weston-Petrides, R. E. Lovegrove, H. S. Tilney, et al., "Comparison of Outcomes after Restorative Proctocolectomy with or without Defunctioning Ileostomy," Archives of Surgery, Vol. 143, No. 4, 2008, pp. 406-412. doi:10.1001/archsurg.143.4.406

[48] S. M. Feinberg, D. G. Jagelman, R. G. Sarre, et al., "Spontaneous Resolution of Rectal Polyps in Patients with Familial Polyposis Following Abdominal Colectomy and Ileorectal Anastomosis,” Diseases of the Colon \& Rectum, Vol. 31, No. 3, 1988, pp. 169-175. doi:10.1007/BF02552541

[49] H. T. Lynch, A. G. Thorson and T. Smyrk, "Rectal Cancer after Prolonged Sulindac Chemoprevention: A Case Report,” Cancer, Vol. 75, No. 4, 1995, pp. 936-938. doi:10.1002/1097-0142(19950215)75:4<936::AID-CNCR 2820750407>3.0.CO;2-Q

[50] A. Kartheuser, P. Stangherlin, D. Brandt, C. Remue and C. Sempoux, "Restorative Proctocolectomy and Ileal PouchAnal Anastomosis for Familial Adenomatous Polyposis Revisited," Familial Cancer, Vol. 5, No. 3, 2006, pp. 241-260. doi:10.1007/s10689-005-5672-4

[51] A. E. M’Koma, H. L. Moses and S. E. Adunyah, "Inflammatory Bowel Disease-Associated Colorectal Cancer: Proctocolectomy Andmucosectomy Does not Necessarily Eliminate Pouch Related Cancer Incidences,” International Journal of Colorectal Disease, Vol. 26, No. 5, 2011, pp. 533-552. doi:10.1007/s00384-011-1137-4

[52] H. J. de Silva, P. R. Millard, N. Soper, M. Kettlewell, N. Mortensen and D. P. Jewell, "Effects of the Faecal Stream and Stasis on the Ileal Pouch Mucosa,” Gut, Vol. 32, No.
10, 1991, pp. 1166-1169. doi:10.1136/gut.32.10.1166

[53] J. S. Wu, P. Paul, E. A. McGannon and J. M. Church, "APC Genotype, Polyp Number, and Surgical Options in Familial Adenomatous Polyposis,” Annals of Surgery, Vol. 227, No. 1, 1998, pp. 57-62. doi:10.1097/00000658-199801000-00009

[54] O. C. Will, J. Robinson, T. Gunther, R. K. Phillips, S. K. Clark and I. Tomlinson, "APC Mutation Spectrum in Ileoanal Pouch Polyps Resembles that of Colorectal Polyps," The British Journal of Surgery, Vol. 95, No. 6, 2008, pp. 765-769. doi:10.1002/bjs.6110

[55] B. Veress, F. P. Reinholt, K. Lindquist and L. Liljeqvist, "Different Types of Mucosal Adaptation in the Ileal Reservoir after Restorative Proctocolectomy: A Two-Year Follow-Up Study," APMIS: Acta Pathologica, Microbiologica, et Immunologica Scandinavica, Vol. 98, No. 9, 1990, pp. 786-796.

doi:10.1111/j.1699-0463.1990.tb04999.x

[56] B. Veress, F. P. Reinholt, K. Lindquist and L. Liljeqvist, "Prospective Studies of the Mucosa of the Ileoanal Pouch,” Gastroenterology, Vol. 108, No. 3, 1995, pp. 953954. doi:10.1016/0016-5085(95)90490-5

[57] D. Moussata, S. Nancey, M. G. Lapalus, et al., "Frequency and Severity of Ileal Adenomas in Familial Adenomatous Polyposis after Colectomy,” Endoscopy, Vol. 40, No. 2, 2008, pp. 120-125. doi:10.1055/s-2007-995363

[58] B. Prost, G. Poncet, J. Y. Scoazec and J. C. Saurin, "Unusual Complications of Argon Plasma Coagulation,” Gastrointestinal Endoscopy, Vol. 59, No. 7, 2004, pp. 929932. doi:10.1016/S0016-5107(04)01268-4

[59] K. O. Shebani, A. F. Stucchi, J. P. McClung, E. R. Beer, W. W. LaMorte and J. M. Becker, "Role of Stasis and Oxidative Stress in Ileal Pouch Inflammation,” Journal of Surgical Research, Vol. 90, No. 1, 2000, pp. 67-75. doi:10.1006/jsre.2000.5842

[60] A. P. Corfield, B. F. Warren, D. C. Bartolo, S. A. Wagner and J. R. Clamp, "Mucin Changes in Ileoanal Pouches Monitored by Metabolic Labelling and Histochemistry," The British Journal of Surgery, Vol. 79, No. 11, 1992, pp. 1209-1212. doi:10.1002/bjs.1800791139

[61] H. J. de Silva, P. R. Millard, M. Kettlewell, N. J. Mortensen, C. Prince and D. P. Jewell, "Mucosal Characteristics of Pelvic Ileal Pouches,” Gut, Vol. 32, No. 1, 1991, pp. 61-65. doi:10.1136/gut.32.1.61

[62] J. J. De Cosse, S. Bulow, K. Neale, et al., "Rectal Cancer Risk in Patients Treated for Familial Adenomatous Polyposis. The Leeds Castle Polyposis Group,” The British Journal of Surgery, Vol. 79, No. 12, 1992, pp. 13721375. doi:10.1002/bjs.1800791245

[63] C. Penna, A. Kartheuser, R. Parc, et al., "Secondary Proctectomy and Ileal Pouch-Anal Anastomosis after Ileorectal Anastomosis for Familial Adenomatous Polyposis," The British Journal of Surgery, Vol. 80, No. 12, 1993, pp. 1621-1623. doi:10.1002/bjs.1800801246

[64] I. Heiskanen and H. J. Jarvinen, "Fate of the Rectal Stump after Colectomy and Ileorectal Anastomosis for Familial Adenomatous Polyposis," International Journal of Colorectal Disease, Vol. 12, No. 1, 1997, pp. 9-13. doi:10.1007/s003840050070 
[65] C. Soravia, L. Klein, T. Berk, B. I. O’Connor, Z. Cohen and R. S. McLeod, "Comparison of Ileal Pouch-Anal Anastomosis and Ileorectal Anastomosis in Patients with Familial Adenomatous Polyposis," Diseases of the Colon \& Rectum, Vol. 42, No. 8, 1999, pp. 1028-1033. doi:10.1007/BF02236696

[66] J. C. Saurin, B. Napoleon, G. Gay, et al., "Endoscopic Management of Patients with Familial Adenomatous Polyposis (FAP) Following a Colectomy,” Endoscopy, Vol. 37, No. 5, 2005, pp. 499-501. doi:10.1055/s-2005-861295

[67] J. M. Church, J. R. Oakley and J. S. Wu, "Pouch Polyposis after Ileal Pouch-Anal Anastomosis for Familial Adenomatous Polyposis: Report of a Case,” Diseases of the Colon \& Rectum, Vol. 39, No. 5, 1996, pp. 584-586. doi:10.1007/BF02058717

[68] A. C. Schulz, C. Bojarski, H. J. Buhr and A. J. Kroesen, "Occurrence of Adenomas in the Pouch and Small Intestine of FAP Patients after Proctocolectomy with Ileoanal Pouch Construction,” International Journal of Colorectal Disease, Vol. 23, No. 4, 2008, pp. 437-441. doi:10.1007/s00384-007-0422-8

[69] Z. Yan, G. Liao and H. Pei, "Surgical Treatment of Familial Adenomatous Polyposis: Experience from a Single Institution in China," Asia-Pacific Journal of Clinical Oncology, Vol. 8, No. , 2012, pp. e23-e28.

[70] F. H. Remzi, V. W. Fazio, E. Gorgun, et al., "The Outcome after Restorative Proctocolectomy with or without Defunctioning Ileostomy,” Diseases of the Colon \& Rectum, Vol. 49, No. 4, 2006, pp. 470-477. doi:10.1007/s10350-006-0509-2

[71] K. O. Olsen, M. Joelsson, S. Laurberg and T. Oresland, "Fertility after Ileal Pouch-Anal Anastomosis in Women with Ulcerative Colitis," The British Journal of Surgery, Vol. 86, No. 4, 1999, pp. 493-495. doi:10.1046/j.1365-2168.1999.01076.x

[72] M. Pignone, M. Rich, S. M. Teutsch, A. O. Berg and K. N. Lohr, "Screening for Colorectal Cancer in Adults at Average Risk: A Summary of the Evidence for the U.S. Preventive Services Task Force," Annals of Internal Medicine, Vol. 137, No. 2, 2002, pp. 132-141. doi:10.7326/0003-4819-137-2-200207160-00015

[73] A. C. von Roon, P. P. Tekkis, R. E. Lovegrove, K. F. Neale, R. K. Phillips and S. K. Clark, "Comparison of Outcomes of Ileal Pouch-Anal Anastomosis for Familial Adenomatous Polyposis with and without Previous Ileorectal Anastomosis," The British Journal of Surgery, Vol. 95, No. 4, 2008, pp. 494-498. doi:10.1002/bjs.6005

[74] C. Soravia, B. I. O’Connor, T. Berk, R. S. McLeod and Z. Cohen, "Functional Outcome of Conversion of Ileorectal Anastomosis to Ileal Pouch-Anal Anastomosis in Patients with Familial Adenomatous Polyposis and Ulcerative Colitis," Diseases of the Colon \& Rectum, Vol. 42, No. 7, 1999, pp. 903-908. doi:10.1007/BF02237099

[75] S. R. Brown, D. Donati and F. Seow-Choen, "Rectal Cancer after Mucosectomy for Ileoanal Pouch in Familial Adenomatous Polyposis: Report of a Case,” Diseases of the Colon \& Rectum, Vol. 44, No. 11, 2001, pp. 17141715. doi:10.1007/BF02234397

[76] J. Bjork, H. Akerbrant, L. Iselius, et al., “Outcome of
Primary and Secondary Ileal Pouch-Anal Anastomosis and Ileorectal Anastomosis in Patients with Familial Adenomatous Polyposis," Diseases of the Colon \& Rectum, Vol. 44, No. 11, 2001, pp. 984-992. doi:10.1007/BF02235487

[77] S. D. McLaughlin, S. K. Clark, P. P. Tekkis, P. J. Ciclitira and R. J. Nicholls, "Review Article: Restorative Proctocolectomy, Indications, Management of Complications and Follow-Up: A Guide for Gastroenterologists," Alimentary Pharmacology \& Therapeutics, Vol. 27, No. 10, 2008, pp. 895-909.

doi:10.1111/j.1365-2036.2008.03643.x

[78] R. K. Phillips and A. D. Spigelman, "Can We Safely Delay or Avoid Prophylactic Colectomy in Familial Adenomatous Polyposis?" The British Journal of Surgery, Vol. 83, No. 6, 1996, pp. 769-770. doi:10.1002/bjs.1800830613

[79] P. van Duijvendijk, J. F. Slors, C. W. Taat, P. Oosterveld and H. F. Vasen, "Functional Outcome after Colectomy and Ileorectal Anastomosis Compared with Proctocolectomy and Ileal Pouch-Anal Anastomosis in Familial Adenomatous Polyposis," Annals of Surgery, Vol. 230, No. 5, 1999, pp. 648-654. doi:10.1097/00000658-199911000-00006

[80] M. V. Madden, K. F. Neale, R. J. Nicholls, et al., "Comparison of Morbidity and Function after Colectomy with Ileorectal Anastomosis or Restorative Proctocolectomy for Familial Adenomatous Polyposis," The British Journal of Surgery, Vol. 78, No. 7, 1991, pp. 789-792. doi:10.1002/bjs.1800780708

[81] R. Farouk, J. H. Pemberton, B. G. Wolff, R. R. Dozois, S. Browning and D. Larson, "Functional Outcomes after Ileal Pouch-Anal Anastomosis for Chronic Ulcerative Colitis," Annals of Surgery, Vol. 231, No. 6, 2000, pp. 919-926. doi:10.1097/00000658-200006000-00017

[82] J. Nicholls, "Quality of Life after Restorative Proctocolectomy for Familial Adenomatous Polyposis," Colorectal Disease, Vol. 13, No. 11, 2011, pp. 1201-1202. doi:10.1111/j.1463-1318.2011.02802.x

[83] A. Sinha, P. P. Tekkis, D. C. Gibbons, R. K. Phillips and S. K. Clark, "Risk Factors Predicting Desmoid Occurrence in Patients with Familial Adenomatous Polyposis: A Meta-Analysis," Colorectal Disease, Vol. 13, No. 11, 2011, pp. 1222-1229. doi:10.1111/j.1463-1318.2010.02345.x

[84] S. Maartense, M. S. Dunker, J. F. Slors, et al., "HandAssisted Laparoscopic versus Open Restorative Proctocolectomy with Ileal Pouch Anal Anastomosis: A Randomized Trial," Annals of Surgery, Vol. 240, No. 6, 2004, pp. 984-991. doi:10.1097/01.sla.0000145923.03130.1c

[85] D. Antolovic, P. Kienle, H. P. Knaebel, et al., "Totally Laparoscopic versus Conventional Ileoanal Pouch Procedure-Design of a Single-Centre, Expertise Based Randomised Controlled Trial to Compare the Laparoscopic and Conventional Surgical Approach in Patients Undergoing Primary Elective Restorative ProctocolectomyLapConPouch-Trial,” BMC Surgery, Vol. 6, 2006, p. 13. doi:10.1186/1471-2482-6-13

[86] J. N. Primrose, P. Quirke and D. Johnston, “Carcinoma of the Ileostomy in a Patient with Familial Adenomatous 
Polyposis,” The British Journal of Surgery, Vol. 75, 1988, p. 384. doi:10.1002/bjs.1800750430

[87] I. Heiskanen, T. Luostarinen and H. J. Jarvinen, “Impact of Screening Examinations on Survival in Familial Adenomatous Polyposis," Scandinavian Journal of Gastroenterology, Vol. 35, No. 3, 2000, pp. 1284-1287.

[88] S. A. Mulder, M. E. Van Leerdam, R. J. Ouwendijk, D. J. Bac, R. W. Giard and E. J. Kuipers, "Attendance at Surveillance Endoscopy of Patients with Adenoma or Colorectal Cancer," Scandinavian Journal of Gastroenterology, Vol. 42, No. 1, 2007, pp. 66-71.

[89] V. de Jonge, J. Sint Nicolaas, M. E. van Leerdam, E. J. Kuipers and S. J. Veldhuyzen van Zanten, "Systematic Literature Review and Pooled Analyses of Risk Factors for Finding Adenomas at Surveillance Colonoscopy," Endoscopy, Vol. 43, No. 7, 2011, pp. 560-572.

[90] S. A. Mulder, R. J. Ouwendijk, M. E. van Leerdam, F. M. Nagengast and E. J. Kuipers, "A Nationwide Survey Evaluating Adherence to Guidelines for Follow-Up after Polypectomy or Treatment for Colorectal Cancer," Journal of Clinical Gastroenterology, Vol. 42, No. 5, 2008, pp. 487-492. doi:10.1097/MCG.0b013e31809e703c

[91] M. L. Arvanitis, D. G. Jagelman, V. W. Fazio, I. C. Lavery and E. McGannon, "Mortality in Patients with Familial Adenomatous Polyposis," Diseases of the Colon \& Rectum, Vol. 33, No. 8, 1990, pp. 639-642. doi:10.1007/BF02150736

[92] L. A. Belchetz, T. Berk, B. V. Bapat, Z. Cohen and S. Gallinger, "Changing Causes of Mortality in Patients with Familial Adenomatous Polyposis," Diseases of the Colon \& Rectum, Vol. 39, No. 4, 1996, pp. 384-387. doi:10.1007/BF02054051

[93] F. G. Campos, A. R. Imperiale, V. E. Seid, et al., "Rectal and Pouch Recurrences after Surgical Treatment for Familial Adenomatous Polyposis,” Journal of Gastrointestinal Surgery, Vol. 13, No. 1, 2009, pp. 129-136. doi:10.1007/s11605-008-0606-8

[94] K. P. Nugent, A. D. Spigelman and R. K. Phillips, "Life Expectancy after Colectomy and Ileorectal Anastomosis for Familial Adenomatous Polyposis," Diseases of the Colon \& Rectum, Vol. 36, No. 11, 1993, pp. 1059-1062.

[95] J. C. Hoehner and A. M. Metcalf, "Development of Invasive Adenocarcinoma following Colectomy with Ileoanal Anastomosis for Familial Polyposis Coli," Diseases of the Colon \& Rectum, Vol. 37, No. 8, 1994, pp. 824-828. doi:10.1007/BF02050149

[96] A. von Herbay, J. Stern and C. Herfarth, "Pouch-Anal Cancer after Restorative Proctocolectomy for Familial Adenomatous Polyposis," The American Journal of Surgical Pathology, Vol. 20, No. 8, 1996, pp. 995-999. doi:10.1097/00000478-199608000-00008

[97] H. Vuilleumier, N. Halkic, R. Ksontini and M. Gillet, "Columnar Cuff Cancer after Restorative Proctocolectomy for Familial Adenomatous Polyposis,” Gut, Vol. 47, No. , 2000, pp. 732-734.

[98] B. S. Ooi, F. H. Remzi, T. Gramlich, J. M. Church, M. Preen and V. W. Fazio, "Anal Transitional Zone Cancer after Restorative Proctocolectomy and Ileoanal Anasto mosis in Familial Adenomatous Polyposis: Report of Two Cases,” Diseases of the Colon \& Rectum, Vol. 46, No. 10, 2003, pp. 1418-1423. doi:10.1007/s10350-004-6760-5

[99] B. C. Vrouenraets, P. Van Duijvendijk, W. A. Bemelman, G. J. Offerhaus and J. F. Slors, "Adenocarcinoma in the Anal Canal after Ileal Pouch-Anal Anastomosis for Familial Adenomatous Polyposis Using a Double-Stapled Technique: Report of Two Cases,” Diseases of the Colon \& Rectum, Vol. 47, No. 4, 2004, pp. 530-534. doi:10.1007/s10350-003-0073-y

[100] S. H. Lee, B. K. Ahn, H. K. Chang and S. U. Baek, "Adenocarcinoma in Ileal Pouch after Proctocolectomy for Familial Adenomatous Polyposis: Report of a Case," Journal of Korean Medical Science, Vol. 24, No. 5, 2009, pp. 985-988. doi:10.3346/jkms.2009.24.5.985

[101] F. G. de Campos, R. O. Perez, A. R. Imperiale, V. E. Seid, S. C. Nahas and I. Cecconello, "Evaluating Causes of Death in Familial Adenomatous Polyposis,” Journal of Gastrointestinal Surgery, Vol. 14, No. 12, 2010, pp. 19431949. doi:10.1007/s11605-010-1288-6

[102] F. Tonelli, F. Ficari, T. Bargellini and R. Valanzano, "Ileal pouch Adenomas and Carcinomas after Restorative Proctocolectomy for Familial Adenomatous Polyposis," Diseases of the Colon \& Rectum, Vol. 55, No. 3, 2012, pp. 322-329. doi:10.1097/DCR.0b013e318241e6f2

[103] A. Makni, F. Chebbi, W. Rebai, S. Ayadi, M. Fekih, M. Jouini, M. Kacem and Z. Ben Safta, "Adenocarcinoma Arising in the ' $\mathrm{J}$ ' Pouch after Total Proctocolectomy for Familial Polyposis Coli,” Tunis Medical, Vol. 90, No. 1, 2012, pp. 80-81.

[104] T. Banasiewicz, R. Marciniak, E. Kaczmarek, P. Krokowicz, J. Paszkowski, A. Lozynska-Nelke, P. Gronek, A. Plawski and M. Drews, "The Prognosis of Clinical Course and the Analysis of the Frequency of the Inflammation and Dysplasia in the Intestinal J-Pouch at the Patients after Restorative Proctocolectomy Due to FAP," International Journal of Colorectal Disease, Vol. 26, No. 9, 2011, pp. 1197-1203. doi:10.1007/s00384-011-1241-5

[105] F. G. Campos, A. Habr-Gama, D. R. Kiss, E. V. da Silva, V. Rawet, A. R. Imperiale, R. Perez, J. H. da Silva, A. H. Sousa Jr and J. Gama-Rodrigues, “Adenocarcinoma after Ileoanal Anastomosis for Familial Adenomatous Polyposis: Review of Risk Factors and Current Surveillance Apropos of a Case,” Journal of Gastrointestinal Surgery, Vol. 9, No. 5, 2005, pp. 695-702. doi:10.1016/j.gassur.2004.10.017

[106] K. A. Booij, E. M. Mathus-Vliegen, J. A. Taminiau, F. J. Ten Kate, J. F. Slors, M. M. Tabbers and D. C. Aronson, "Evaluation of 28 Years of Surgical Treatment of Children and Young Adults with Familial Adenomatous Polyposis,” Journal of Pediatric Surgery, Vol. 45, No. 3, 2010, pp. 525-532. doi:10.1016/j.jpedsurg.2009.06.017

[107] P. Friederich, A. E. de Jong, L. M. Mathus-Vliegen, E. Dekker, H. H. Krieken, J. Dees, F. M. Nagengast and H. F. Vasen, "Risk of Developing Adenomas and Carcinomas in the Ileal Pouch in Patients with Familial Adenomatous Polyposis," Clinical Gastroenterology and Hepatology, Vol. 6, No. 11, 2008, pp. 1237-1242. doi:10.1016/j.cgh.2008.06.011 